\title{
Correction to: Understanding the Family Impact of Autism Spectrum Disorder in a Racially and Ethnically Diverse Sample: Findings from the National Survey of Children with Special Health Care Needs
}

\author{
Teal W. Benevides ${ }^{1}$ (D) Jiwon Lee . Nonyé A. O. Nwosu $^{3} \cdot$ Jessica Franks $^{4}$
}

Published online: 2 April 2019

๑) Springer Science+Business Media, LLC, part of Springer Nature 2019

\section{Correction to: Maternal and Child Health Journal https://doi.org/10.1007/s10995-018-02724-x}

The original version of this article unfortunately contained a mistake. The copyright permission below in Table 2 was inadvertently not published in the article.

Reproduced with permission from Pediatrics, Vol. 137, Page 10, Copyright (C) 2016 by the AAP.

The original article has been corrected.

Publisher's Note Springer Nature remains neutral with regard to jurisdictional claims in published maps and institutional affiliations.

The original article can be found online at https://doi.org/10.1007/ s10995-018-02724-x.

Teal W. Benevides

tbenevides@augusta.edu

1 Department of Occupational Therapy, College of Allied Health Professions, Augusta University, 987 St. Sebastian Way, EC-2324, Augusta, GA 30912, USA

2 School of Nursing, Byrdine F. Lewis College of Nursing and Health Professions, Georgia State University, Atlanta, GA, USA

3 Department of Psychology, College of Arts and Sciences, Georgia State University, Atlanta, GA, USA

4 Center for Leadership in Disability, Georgia Leadership Education in Neurodevelopmental Disabilities Program, Georgia State University, Atlanta, GA, USA 